\title{
Application of Example Non Example Method Based on Audio Visual Themed Nature Media in Poem Learning for Students in BIPA
}

\author{
Sacandra Aji Rivaldi ${ }^{1}$ Nurhannah Widianti ${ }^{2}$ \\ Triwahyu Puspa Huda ${ }^{3}$ and Mila Larina Melandari ${ }^{4}$ \\ ${ }^{1}$ IAIN Syekh Nurjati, Indonesia, ${ }^{2}$ IAIN Syekh Nurjati, Indonesia, ${ }^{3}$ STKIP Yasika Majalengka, \\ Indonesia, ${ }^{4}$ IAIN Syekh Nurjati, Indonesia \\ ${ }^{1}$ sacandraaji@yahoo.com, 2nurhannahw@gmail.com, \\ ${ }^{3}$ puspahuda@gmail.com, 4 mimilarina@gmail.com,
}

\begin{abstract}
This study to describe the application the example non example method based on audio visual themed nature media in poetry learning for BIPA 1 IKMI Cirebon students. The research method used is a descriptive qualitative research method. Based on the results of the study, found the benefits of using this audio visual media in poetry learning for BIPA 1 students at IKMI Cirebon. The benefits of using these learning media are (1) Helping teachers to provide stimulus related to poetry learning (2) Learning more communicative and interesting (3) Facilitating finding ideas for writing poetry (4) Providing new knowledge about new vocabulary.
\end{abstract}

Keywords: Example Non Example Method, Audio Visual, Poem Learning

\section{PENDAHULUAN}

Puisi merupakan interpretasi pengalaman manusia yang diwujudkan dalam bentuk bait. Setiawan dan Andik menyatakan bahwa melalui puisi, seseorang dapat meluapkan isi hati dan kegundahannya maupun kegalauan atau kegirangan tertentu [1]. Adapun pembelajaran puisi penting untuk dikuasai pembelajar BIPA agar mereka tidak hanya terampil berbahasa, melainkan juga bersastra. Selain itu, pembelajaran ini menurut Wahyudi mengajarkan pembelajar untuk memiliki daya kritis, mengungkapkan ide-ide tanpa takut, dan menyusunnya dengan penuh makna [2]. Selaras dengan pernyataan tersebut, Prayitno menegaskan bahwa tujuan pembelajaran puisi, yaitu menstimulus pembelajar supaya mampu mengungkapkan pengalamannnya, kepekaannya terhadap lingkungan, kemudian mengungkapkannya dalam bentuk puisi [3]. Misalnya, pembelajar bisa mengabadikan keindahan Indonesia atau pengalamannya belajar di Indonesia dalam bentuk puisi yang indah.

Menurut beberapa pembelajar BIPA yang diwawancarai, belajar menulis puisi merupakan kegiatan yang cukup sulit karena mereka harus lebih mengembangkan imajinasi dan menuliskannya dalam bentuk bait. Untuk menemukan ide, mereka harus mempunyai pengalaman, sedangkan mereka belum banyak pengalaman di Indonesia. Problematika tersebut diungkapkan pula oleh Safian, Malakar, dan Kalajahi kebahasaan mencakup kosakata dan pengimplementasiannya adalah masalah besar bagi sebagian pemelajar [4]. Huda pun 
menyatakan salah satu kendala seseorang dalam menulis, yakni sulitnya mencari dan menentukan bahan tulisan karena minimnya pengalaman [5]. Kalau pun memiliki pengalaman mereka masih kesulitan untuk merangkai kata-kata, menemukan kata kias, majas dan lain-lain. Hal ini selaras dengan Widodo, dkk. mengungkapkan bahwa pembelajar seringkali buntu untuk memunculkan gagasan dan sulit menentukan diksi serta gaya bahasa yang pas sehingga menimbulkan kemonotonan [6]. Dalam pembelajaran bahasa, kajian demikian menarik. Hal itu sejalan dengan Wangru bahwa kajian kosakata sangat menarik dan menjadi sebuah tantangan [7]. Oleh karena itu, media dan materi pembelajaran harus disiapkan guru dengan apik. Hal ini selaras dengan Zamahsari, Roffi'uddin, Widodo bahwa pemahaman terhadap kosakata,afiksasi, struktur kalimat, dan wacana dalam bahasa Indonesia harus dikemas dengan baik agar pembelajaran menjadi lebih bermakna [8].

Berdasarkan hal tersebut, maka untuk mengembangkan imajinasi pembelajar dan mengekfektifkan pembelajaran puisi diperlukan motivasi dari guru. Selaras dengan itu, Walsh menyatakan "has examined the ways in which teachers, through their choice of language forms, motivate or demotivate studentse participation in face-to-face classroom communication" [9] Selain motivasi, pengajar perlu juga menerapkan metode dan media pembelajaran yang tepat. Salah satunya, yaitu menerapkan metode exemple non exemple berbasis media audio visual. Pernyataan ini ditegaskan pula oleh Walqui bahwa menghadirkan objek seperti foto, penggalan film, dan lainnya dapat membuat pembelajaran bahasa mudah dipahami [10].

Dengan media audio visual tersebut pembelajar BIPA akan lebih menemukan ide dan mengembangkan imajinasi sesuai dengan yang dilihat pada video tersebut. Selain itu, menurut Ode penggunaan media audio visual dalam pembelajaran dapat meningkatkan pemahaman yang lebih baik dan menciptakan keseimbangan emosional dengan memberi ruang untuk pengembangan diri [11]. Bahkan Widianti media pembelajaran membuat proses belajar menarik dan bisa meningkatkan semangat serta hasil belajar siswa [12]. Hal senada pun disampaikan Ramliyana bahwa media pembalajaran komik mampu memberikan pengalaman baru bagi pembelajar BIPA untuk belajar bahasa Indonesia dengan gambar [13].

Sementara itu, metode example non example merupakan metode pembelajaran aktif yang bersifat student center. Suharningshi mengungkapkan bahwa metode tersebut mengarahkan potensi pembelajar dan membantu tercapainya tujuan pembelajaran secara maksimal [14]. Lebih lanjut, Efrizal R., Ria A., dan Didi Y. menyatakan bahwa metode tersebut menstimulus pembelajar secara cepat memahami materi pembelajaran karena hakikatnya metode ini membantu guru membahas materi yang sedang dikaji disertai contoh konkretnya. [15]

\section{METODE PENELITIAN}

Deskriptif kualitatif digunakan pada penelitian ini. Sugiyono menyatakan "metode kualitatif digunakan untuk mendapatkan data yang mendalam, suatu data yang mengandung makna" [16]. Penelitian ini dilakukan di IKMI Cirebon. Subjek penelitian adalah pembelajar BIPA tingkat dasar (level B1). Pengumpulan data menggunakan teknik simak, catat, dan wawancara. Adapun interpretasi data dilakukan dengan paparan deskriptif secara informal sesuai dengan pernyataan Sudaryanto [17]. Setelah data terkumpul, peneliti melakukan uji keabsahan data dengan teknik triangulasi. Triangulasi menurut Moleong adalah "teknik pemerikasaan keabsahan data yang memanfaatkan sesuatu yang lain di luar data itu untuk keperluan pengecekan atau sebagai pembanding terhadap data itu" [18]. "Teknik triangulasi yang paling banyak digunakan ialah pemerikasaan melalui sumber lainnya" [18]. 


\section{HASIL DAN PEMBAHASAN}

Dalam proses pembelajaran, guru membahas tentang unsur-unsur pembangun puisi, kemudian menayangkan video tentang keindahan bahari Indonesia. Setelah itu, mereka bekerja sama untuk membuat satu buah puisi yang bertema keindahan Indonesia. Hal ini dilakukan agar pembelajar memiliki pengalaman dalam menulis puisi tentang alam Indonesia. Penayangan video dalam pembelajaran tersebut guna menstimulus imajinasi pembelajar sebagaimana disampaikan oleh Mathew dan Alidmat behawa pembelajaran dengan berbasis media audiovisual dapat memberikan inspirasi dan motivasi di kelas [19]. Sependapat dengan itu, Widianti pemelajar membutuhkan motivasi untuk belajar agar ia bisa maksimal dalam mengikuti pembelajar [20]. Motivasi ini bisa dilakukan oleh guru dengan cara terus berinovasi.

Adapun, peran tema puisi tersebut sebagai ungkapan kasih kepada Indonesia dan mendorong untuk mengganggumi kekayaan alam Indonesia (Rahmawati, Sudigno dan Saddhono) [21]. Puisi yang sudah jadi tersebut kemudian dianalisis bersama-sama, baik dari segi bahasa maupun maknanya. Setelah itu, barulah guru menayangkan video kedua, yaitu "The Beauty of Indonesia". Pada kegiatan tersebut, pembelajar ditugasi secara mandiri membuat puisi. Berikut ini merupakan hasil puisi karya dua pembelajar BIPA yang berasal dari Madagaskar.

\section{PETANI}

\section{Tanah sawah}

Mereka adalah petani

Yang pengasuh tanah

Mereka yang ahli

Mereka yang benar petani

\section{Sehari-hari mereka \\ Selalu hadir di sana \\ Sehari-hari mereka \\ Berharap banyak hasil dari sawah}

a. Diksi

Analisis puisi berdasarkan struktur fisiknya:

Pemilihan kata yang digunakan Hary (pembelajar 1) berkisah tentang seorang petani. Seperti: sawah, tanah, dan petani.

b. Kata Konkret

Kata konkret yang digunakan Hary (pembelajar 1) tidak memperkabur makna puisi yang hendak disampaikan. Pengarang seperti ingin pembaca merasakan seperti apa yang ia gambarkan dalam puisi tersebut. Hal Ini sesuai dengan pernyataan Nurfaedah bahwa kata konkret dalam puisi menggambarkan suatu kiasan suasana batin yang dapat membangkitkan imaji pembaca [22].

c. Bahasa Figuratif

Bahasa figuratif yang tampak tidak terlalu sulit untuk dimengerti. Kata "sawah" menggambarkan hamparan luas tanaman padi yang membentang.

d. Versifikasi

Dalam puisi ini mengikuti pola puisi kontemporer. Pada bait pertama memiliki pola b-a-a sedangkan pada bait kedua memiliki pola a-a-a.

e. Tipografi

Tipografi pada puisi ini bait pertama beruntun dalam satu baris, begitupun pada bait kedua. Analisis berdasarkan struktur batinnya: 
a. Perasaan

Menurut Ramadhanti dan Diyan perasaan dalam puisi dapat berupa apresiasi, sikap, atau emosi penyair untuk subjek puisi yang ditulisnya, seperti perasaan heran, sedih, gembira, atau suka cita [23].Sementara itu, perasaan pengarang dalam menciptakan puisi ini dapat terlihat pada setiap barisnya. Perasaan yang menggambarkan pengharapan kepada Tuhan agar hasil panen di sawah bisa melimpah dan membahagiakan para petani.

b. Nada dan suasana

Nada dan suasana bercerita dengan mengungkapkan perasaan sedih oleh pengarangnya. Pengarang menceritakan sebuah pengharapan yang dilukiskan di raut wajah para petani.

c. Amanat

Puisi ini menyatakan rasa sedih karena sebuah pengharapan dari para petani.

\author{
INDONESIA \\ Indonesia yang terindah \\ Sudah modern, tapi masih rapi dan bersih \\ Hutan lebat ditutup dengan langit putih \\ Yang membuatnya segar setiap hari
}

\title{
Laut transparan \\ Danau kehidupan \\ Gunung cantik \\ Adu ... terlalu menarik
}

a. Diksi

Analisis puisi berdasarkan unsur fisiknya:

Pemilihan kata yang digunakan Eva berkisah tentang keindahan negara Indonesia. Seperti: danau, gunung, modern, laut, dan hutan. Diksi pada puisi tersebut adalah bahasa konotasi dan bahasa dalam keseharian sehingga maknanya mudah dipahami.

b. Kata Konkret

Eva menggunakan kata konkret, tapi mengaburkan makna puisi yang hendak disampaikan. Pengarang seperti ingin membuat pembaca merasakan seperti apa yang ia tuliskan dalam puisi tersebut. Hal ini sejalan dengan penelitian Kao bahwa kata konkret merupakan salah satu fitur puisi paling menarik estetika modern [24].

c. Citraan

Citraan dalam puisi didominasi dengan citraan visual. Citraan pengelihatan dalam puisi di atas berada baris ketiga "Hutan lebat yang ditutupi oleh langit putih".

d. Gaya Bahasa

Gaya bahasa yang digunakan pada puisi di atas adalah sinekdoke pars prototo. Maknanya penggambaran sebagian untuk mewakili keseluruhan. Majas tersebut terdapat pada baris "Indonesia yang terindah" Indonesia menunjukkan negara yang sangat luas. Indonesia menandakan bahwa wilayah yang memiliki keanekaragaman budaya yang begitu indah. Tidak mungkin, jika pengarang harus menggambarkan tentang keindahan tersebut secara keseluruhan. Maka baris tersebut menggunakan majas sinekdoke pars prototo.

e. Rima dan Irama

Penggunaan bunyi yang digunakan pada puisi tampak pada bunyi akhir puisi yang dominan bunyi /a/. Penggunaan bunyi /a/ yang dominan ini menunjukkan bahwa puisi tersebut menggambarkan kesenangan, kekaguman. Vokal /a/ identik dengan hal yang berkaitan dengan kebahagiaan atau kesenangan terhadap sesuatu [25]. 


\section{SIMPULAN}

Berdasarkan hasil penelitian, menunjukkan bahwa metode dan media yang digunakan dalam penelitian ini sangat membantu pembelajar BIPA 1 di IKMI Cirebon memahami pelajaran menulis puisi. Adapun manfaat yang bisa dihimpun, yakni (1) membantu guru untuk memberikan stimulus terkait pembelajaran puisi, (2) pembelajaran lebih komunikatif dan menarik, (3) memudahkan menemukan ide untuk menulis puisi, (4) memberikan pengetahuan tentang kosa kata baru. Disamping itu ada beberapa rekomendasi yang dapat disampaikan. Pertama, untuk menggunakan metode example non example berbasis audio visual pada BIPA 1 ini perlu menggunakan, video atau film yang menarik dan menyentuh disesuaikan dengan usia pembelajar.

\section{REFERENCES}

[1] W. S. dan A. Yulianto, "JURNAL PENA INDONESIA Jurnal Bahasa dan Sastra Indonesia serta Pengajarannya,” J. Bhs. dan Sastra Indones. serta Pengajarannya, vol. 3, no. 1, pp. 42-58, 2017.

[2] D. Wahyudi, "Peningkatan Keterampilan Menulis Puisi Dengan Media Lagu Pada Siswa Kelas V," e-Journal Pembelajaran Inovasi, J. Ilm. Pendidik. Dasar, vol. 1, no. 1, pp. 514-523, 2016.

[3] H. W. Prayitno, "Jurnal Pendidikan Bahasa dan Sastra FKIP,” vol. 1, no. 1, 2012.

[4] N. H. dan S. M. Safian, "Exploring Vocabulary Learning Strategies Used by UPM TESL Undergraduates," Adv. Lang. Lit. Stud., 2014.

[5] Triwahyu Puspa Huda, "Pengembangan Model Problem Based Learning dengan Pengolahan dan Pemanfaatan Informasi dalam Pembelajaran Menulis," Universitas Pendidikan Indonesia, 2017.

[6] J. Widodo, "perpustakaan.uns.ac.id digilib.uns.ac.id," 2013.

[7] C. Wangru, "Vocabulary Teaching Based on Semantic-Field," J. Educ. Learn., vol. 5, no. 3 , p. $64,2016$.

[8] G. K. Zamahsari, A. H. Roffi'uddin, and W. Hs, "Implementasi Scaffolding dalam Pembelajaran BIPA di Kelas Pemula,”J. Pendidik., vol. 4, no. 1, pp. 68-78, 2019.

[9] S. Walsh, "Construction or obstruction: teacher talk and learner involvement in the EFL classroom," Lang. Teach. Res., vol. 6, no. 1, pp. 3-23, 2002.

[10] A. Walqui, "Scaffolding Instruction for English Language Learners: A Conceptual Framework," Int. J. Biling. Educ. Biling., vol. 9, no. 2, pp. 159-180, 2006.

[11] E. O. Ode, "Impact of Audio-Visual (AVs) Resources on Teaching and Learning in Some Selected Private Secondary Schools in Makurdi," Int. J. Res. Humanit. Arts Lit. (IMPACT IJRHAL), vol. 2, no. 5, pp. 195-202, 2014.

[12] N. Widianti, "Penerapan Metode Demonstrasi Bermediakan Video Pidato Soekarno Dalam Pembelajaran Berpidato Pada Siswa Kelas X SMA Negeri 1 Lemahabang Cirebon," JP-BSI (Jurnal Pendidik. Bhs. dan Sastra Indones., vol. 1, no. 2, p. 73, 2016.

[13] R. Ramliyana, "Penggunaan buku komik 'bahasa I ndonesia bagi penutur asing (BIPA) 1 ' dan pengaruhnya terhadap hasil belajar peserta BIPA," J. Bhs. Indones. bagi Penutur Asing, vol. 1, no. 1, pp. 30-40, 2019.

[14] I. Suharningsih, "Jurnal Onoma: Pendidikan, Bahasa dan Sastra PBSI FKIP Universitas Cokroaminoto Palopo Volume 4 Nomor 2 ISSN 2443-3667," J. Onoma Pendidikan, Bhs. dan Sastra, vol. 4, pp. 157-172, 2010. 
[15] D. Y. Efrizal Rian, Ria Ariesta, "Perbedaan Kemampuan Menulis Puisi dengan Model Pembelajaran Example Non Example dengan Menggunakan Model Pembelajaran Konvensional Siswa Kelas VIII SMP Negeri 7 Kota Bengkulu," J. Chem. Inf. Model., vol. 2, pp. 185-189, 2018.

[16] Sugiyono, Metode Penelitian Kualitatif Kuantitatif dan R\&D. Bandung: Alfabeta, 2011.

[17] Sudaryanto, Metode dan Aneka Teknik Analisis Bahasa. Yogyakarta: Diandra Primamitra, 2015.

[18] Moleong, Metodologi Penelitian Kualitatif. Bandung: Remaja Rosdakarya, 2010.

[19] N. G. Mathew and A. O. H. Alidmat, "A Study on the Usefulness of Audio-Visual Aids in EFL Classroom: Implications for Effective Instruction," International Journal of Higher Education, vol. 2, no. 2. 2013.

[20] dkk Widianti, Nurhannah, "METABAHASA Jurnal Pendidikan Bahasa dan Sastra Indonesia TEKS EDITORIAL SEBAGAI BAHAN AJAR BAHASA INDONESIA," Metabahasa, vol. 2, pp. 47-70, 2019.

[21] F. P. Rahmawati, A. Sudigdo, and K. Saddhono, "Implementation of literacy wrote poetry with nature theme as a means of strengthening character love Indonesia," vol. 2017, no. October, pp. 21-22, 2017.

[22] Nurfaedah, "Keefektifan Media Audio Visual dalam Meningkatkan Kompetensi Siswa Sekolah Menengah Pertama dalam Menulis Puisi Effectiveness of Audio Visual Media to Improve the Competence of Junior High School Students in Writing Poetry," Indones. J. Instr. Media Model, vol. 1, pp. 26-34, 2019.

[23] D. P. Y. Ramadhanti, Dina, "No Title," Cakrawala Pendidik. J. Ilm. Pendidik., pp. 436446, 2018.

[24] J. Kao and D. Jurafsky, "A Computational Analysis of Style, Affect, and Imagery in Contemporary Poetry,” 1st Work. Comput. Linguist. Lit. (CLfL 2012), pp. 8-17, 2012.

[25] K. Saddhono, Suhartatik, Bagiya, Widodo, and H. Wahyono, "Learning vocabularies using multimedia-based Teaching Indonesian to Speakers of Other Languages (TISOL)," in Journal of Physics: Conference Series, 2019, p. 012108. 